\title{
Surface Phase Transformation in Austenitic Stainless Steel Induced by Cyclic Oxidation in Humidified Air
}

Mattias Calmunger, Robert Eriksson, Guocai Chai, Sten Johansson and Johan Moverare

\author{
Linköping University Post Print
}

\section{Tweet}

N.B.: When citing this work, cite the original article.

Original Publication:

Mattias Calmunger, Robert Eriksson, Guocai Chai, Sten Johansson and Johan Moverare, Surface Phase Transformation in Austenitic Stainless Steel Induced by Cyclic Oxidation in Humidified Air, 2015, Corrosion Science, (100), 524-534.

http://dx.doi.org/10.1016/j.corsci.2015.08.030

Copyright: Elsevier

http://www.elsevier.com/

Postprint available at: Linköping University Electronic Press

http://urn.kb.se/resolve?urn=urn:nbn:se:liu:diva-122008 


\title{
Surface phase transformation in austenitic stainless steel induced by cyclic oxidation in humidified air
}

\author{
Mattias Calmunger ${ }^{\mathrm{a}, *}$, Robert Eriksson ${ }^{\mathrm{b}}$, Guocai Chai ${ }^{\mathrm{a}, \mathrm{c}}$, Sten Johansson ${ }^{\mathrm{a}}$, \\ Johan Moverare ${ }^{\mathrm{a}}$ \\ ${ }^{a}$ Department of Management and Engineering, Linköping University, 58183 Linköping, \\ Sweden \\ ${ }^{b}$ Siemens AG, Huttenstr. 12, 10553 Berlin, Germany \\ ${ }^{c}$ AB Sandvik Materials Technology REDD center, 81181 Sandviken, Sweden
}

\begin{abstract}
The formation of $\alpha^{\prime}$ martensite at the surface of an AISI 304 stainless steel subjected to cyclic heating in humidified air is reported. The $\alpha^{\prime}$ martensite formed during the cooling part of the cyclic tests due to local depletion of $\mathrm{Cr}$ and $\mathrm{Mn}$ and transformed back to austenite when the temperature again rose to $650{ }^{\circ} \mathrm{C}$. The size of the $\alpha$ martensite region increased with increasing number of cycles. Thermodynamical simulations were used as basis for discussing the formation of $\alpha^{\prime}$ martensite. The effect of the $\alpha^{\prime}$ martensite on corrosion is also discussed.
\end{abstract}

Keywords: Stainless steel, Thermal cycling, SEM, Oxidation, High temperature corrosion

\footnotetext{
*Corresponding author. Phone:+4613281197, E-mail address: mattias.calmunger@liu.se,
} 


\section{Introduction}

To meet the demands of tomorrow's energy production, power plants need to be more flexible in the consideration of fuels and operation conditions. The materials used in the next generation of power plants will be exposed to higher temperatures and pressures, more corrosive environment and many start-and-stop cycles $[1,2]$.

The widely used austenitic stainless steel AISI 304 exhibits good oxidation resistance at elevated temperatures in dry air due to the formation of a protective $\mathrm{Cr}$-rich $(\mathrm{Cr}, \mathrm{Fe})_{2} \mathrm{O}_{3}$ scale [3]. However, at temperatures above 600 ${ }^{\circ} \mathrm{C}$ the addition of water vapour has a detrimental effect on the protectiveness of the Cr-rich $(\mathrm{Cr}, \mathrm{Fe})_{2} \mathrm{O}_{3}[4,5,6,7,8,9,10,11,12]$. This because the water vapour reacts with the Cr-rich oxide which eventually causes Cr depletion due to vaporization and non-protective breakaway oxides $[3,4,5,6,7,8,9$, $10,11,12]$ according to the following reaction $[9,12]$ :

$\frac{1}{2}\left(\mathrm{Fe}_{1-x}, \mathrm{Cr}_{x}\right)_{2} \mathrm{O}_{3}(\mathrm{~s})+\frac{3}{4} x \mathrm{O}_{2}(\mathrm{~g})+x \mathrm{H}_{2} \mathrm{O} \rightarrow x \mathrm{CrO}_{2}(\mathrm{OH})_{2}(\mathrm{~g})+\frac{1}{2}(1-x) \mathrm{Fe}_{2} \mathrm{O}_{3}(\mathrm{~s})$

Thermal cycling with the addition of water vapour accelerates the onset of breakaway oxidation $[13,14]$. The formation of non-protective breakaway oxides and the protectiveness of the Cr-rich oxide depend on the ratio between the $\mathrm{Cr}$ depletion and the supply of $\mathrm{Cr}$ by diffusion from the alloy [5, 15, $9,11]$. There are different approaches to improve the supply of Cr to the protective scale, where increased $\mathrm{Cr}$ content is a common solution $[6,16$, 13]. Another possible solution is grain refinement at the surface, using, for instance, nanocrystalline coatings $[11,14]$ or plastic deformation techniques 
[17] to improve the supply of $\mathrm{Cr}$ to the protective oxide scale. The grain refinement produces a large number of grain boundaries that increase the diffusion of Cr to the surface $[18,19,20]$.

The surface properties clearly govern the corrosion process. The surface properties of AISI 304-type stainless steels are influenced by the formation of $\alpha^{\prime}$ martensite (BCC) that forms from austenite (FCC) at the surface during cooling from elevated temperature $[21,22,23,24]$. The $\alpha^{\prime}$ martensite formation in AISI 304-type stainless steels has previously been attributed to Cr depletion at grain boundaries through carbide formation [21] and the subsequent increase of the temperature of martensitic transformation $\left(M_{s}\right)$ [21, 23, 24]. Mukhopadhyay et al. [22] have shown, using acoustic emission, that the formation is martensitic, as opposed to diffusion controlled transformation. The $\alpha^{\prime}$ martensite formation also occur at other locations than grain boundaries; Susan et al. [23] have reported formation of $\alpha^{\prime}$ martensite at the surface when cooling to room temperature after oxidation at 1000$1100{ }^{\circ} \mathrm{C}$ in a low $\mathrm{pO}_{2}$ environment. The $\alpha^{\prime}$ martensite formation at the surface occurs due to depletion of $\mathrm{Cr}, \mathrm{Mn}$ and $\mathrm{Si}$ which increases the $M_{s}$ temperature making the formation of $\alpha^{\prime}$ martensite above room temperature possible [23]. La Fontaine et al. [24] showed that $\mathrm{Cr}$ depletion from oxidation during thermal cycling up to $970{ }^{\circ} \mathrm{C}$ in air was responsible for $\alpha$ ' martensite formation which gave intergranular corrosion causing intergranular cracking as a consequence. However, the influence of thermal cycling in a water vapour environment on the formation of $\alpha^{\prime}$ martensite is not yet fully understood. Consequently, more research needs to be conducted to investigate the influence of $\alpha^{\prime}$ martensite at the surface on corrosion. 
The purpose of the present study is to investigate the formation of $\alpha$ ' martensite at the surface of an AISI 304 stainless steel during thermal cycling in a water vapour environment. The influence of cyclic oxidation on formation of $\alpha^{\prime}$ martensite is discussed using thermodynamical simulations. The effect of the $\alpha^{\prime}$ martensite on corrosion is also discussed.

\section{Experimental procedures}

\subsection{Oxidation}

The samples were made of an AISI 304 stainless steel with the nominal composition (in wt.\%): 0.015 C, 0.35 Si, 1.2 Mn, $18.3 \mathrm{Cr}, 10.3 \mathrm{Ni}, 0.3 \mathrm{Cu}, 0.05$ W, $0.01 \mathrm{Nb}, 0.07 \mathrm{~N}$ and Fe balance. The material originates from a tube that was manufactured by hot extrusion-cold pilgering and then solution annealed at $1060{ }^{\circ} \mathrm{C}$ for 15 minutes. The used sample geometry was $10 \mathrm{~mm}$ x $10 \mathrm{~mm}$ with a thickness of $5 \mathrm{~mm}$. After cutting the samples, the solution annealing at $1060{ }^{\circ} \mathrm{C}$ for 15 minutes was again applied to the test specimens, followed by grinding on all sides, using a $500 \mathrm{SiC}$-paper, to remove oxides.

Testing in corrosive environment was performed at $650{ }^{\circ} \mathrm{C}$ in a thermal cyclic rig. The specimens rested on a stationary ceramic table and the thermal cycling was accomplished by lowering and rising a furnace over the specimens. Since the specimens rested on the ceramic table, five sides of the specimen were fully exposed to the corrosive medium. All analyses were made on the surface facing upwards. One thermal cycle consisted of a $96 \mathrm{~h}$ dwell time at $650{ }^{\circ} \mathrm{C}$ followed by natural cooling until the specimens reached $100{ }^{\circ} \mathrm{C}$ which took approximately 18 minutes; Fig. 1 shows the cooling curve as measured on one of the specimens. Specimens subjected to 2, 5, 10 and 
20 thermal cycles were used in the investigation.

During the hot part of the cycle, water was introduced as an air-water mist which was sprayed into the furnace (not directly onto the specimens). The water mist immediately evaporated as it was sprayed into the furnace and increased the water vapour content in the furnace chamber. The amount of water vapour was controlled by the water-to-air ratio in the water mist and was adjusted to $\sim 15 \mathrm{~mol} \%$. This was achieved by controlling the water inlet flow into the air stream, as outlined in Fig. 2. Since the furnace was not airtight, a new burst of air-water mist was injected every 3rd minute which evaporated and flushed the furnace through with water vapour.

As a reference, an isothermal oxidation test in laboratory air was performed at $650{ }^{\circ} \mathrm{C}$ for 1000 hours.

\subsection{Analytical methods}

\subsubsection{Analytical scanning electron microscopy}

For chemical analysis, energy dispersive spectroscopy (EDS) and wave dispersive spectroscopy (WDS) were used. For microstructural investigation, electron channelling contrast imaging (ECCI) [25] and electron backscatter diffraction (EBSD) were employed. Both chemical and microstructural analyses were performed using a HITACHI SU-70 field emission gun scanning electron microscope (FEG-SEM). EDS and WDS were performed at $20 \mathrm{kV}$ acceleration voltage and a working distance of $15 \mathrm{~mm}$. ECCI was performed at $10 \mathrm{kV}$ acceleration voltage and a working distance of $7 \mathrm{~mm}$. EBSD was measured at $15 \mathrm{kV}$ acceleration voltage and a working distance of $20 \mathrm{~mm}$ using an OXFORD electron backscatter diffraction detector. The HKL software CHANNEL 5 was used for the microstructural evaluation and 
the EBSD-maps were produced using a step size of $0.1 \mu \mathrm{m}$.

\subsubsection{X-ray diffraction}

Grazing incidence (GI) X-ray diffraction (XRD) was used to analyse the crystalline corrosion products. A Philips X'Pert XRD-machine was employed, equipped with grazing incidence beam and a $2 \times 2 \mathrm{~mm}^{2}$ crossed slits attachment. $\mathrm{CuK}_{\alpha}$ radiation was used and the angles of incidence were $2^{\circ}$, $5^{\circ}$ and $10^{\circ}$. The detector measured between $20^{\circ}<2 \theta<80^{\circ}$.

\section{Results}

\subsection{Oxidation during thermal cycling in humidified air}

Various kinds of oxides formed during the thermal cycling in the humidified air. GI-XRD results after 20 cycles showed that $\mathrm{M}_{2} \mathrm{O}_{3}$ oxides, spinel oxides, BCC and FCC phases were present, see Fig. 3. Fig. 4 shows the element distribution of $\mathrm{O}, \mathrm{Fe}, \mathrm{Cr}, \mathrm{Ni}$ and $\mathrm{Mn}$ in the oxide scale after 10 cycles. Table 1 lists the chemical composition in at.\% from EDS point scans taken at the positions labelled A-F in Fig. 4. Four different regions in the oxide could be discerned after 10 cycles: 1) an Fe-rich outer layer (C and D), 2) a local Cr-rich oxide on the metal surface (E), 3) inward growing mixed Cr-, Niand Fe-oxide relatively rich in $\mathrm{Ni}(\mathrm{A})$, and 4) a more shallow inward growing Cr-, Ni- and Fe-oxide lower in Ni (F). The development of the oxides during the cycles is shown in Fig. 5, which displays EDS and WDS analyses of the cross-sections; the linescan starts in the middle of the oxides and goes into the bulk material. In Fig. 6, top-views of the oxidised surfaces are shown. Fig. 6 a) shows a specimen isothermally oxidised in lab air as reference. In 
lab air, the alloy formed a fine-grained Cr-rich oxide. Fig. 6 b)-d) show surfaces oxidised moist air for various number of cycles. Theses specimen formed an outer Fe-rich oxide. Fig. 6 b)-d) also show that the Fe-rich outer oxide coarsened with increasing number of cycles.

Fig. 7 shows light optic microscopy (LOM) images on cross sections near the surfaces. Inward oxidation, caused by isothermal oxidation in air and thermal cycling in the corrosive environment, and $\alpha^{\prime}$ martensite (BCC) can be observed. The oxides are not visible in the LOM images due to the contrast settings; the inward oxidation is indicated in Fig. 7 by arrows. The inward growing oxides increased in area with increasing number of cycles, consuming the bulk material. The FCC matrix was more heavily attacked than the BCC regions.

\subsection{Formation of $\alpha^{\prime}$ martensite}

In Fig. 8 the typical microstructure of solution heat-treated and grind material is shown. No oxides were present since the specimens had not yet undergone the corrosion tests. Fig. 8 b) also displays an inversed pole figure (IPF) EBSD-map and a low angle grain boundery (LAGB) EBSD-map. The

deformation introduced during the grinding can be seen. In Fig. $8 \mathrm{c}$ ), a phase identification EBSD-map shows that the microstructure at the surface only consist of FCC (red color). Since the microstructure in Fig. 8 c) only consists of austenite, it shows that the grinding process did not form any strain-induced martensite.

After isothermal oxidation at $650{ }^{\circ} \mathrm{C}$ for 1000 hours in air, a $\alpha^{\prime}$ martensite (BCC) layer with an approximate thickness of 1-2 $\mu \mathrm{m}$ was observed at the surface of the specimen, as shown in Fig. 9 where FCC corresponds to the 
red color and BCC corresponds to the blue color. The BCC layer was also observed at the surfaces of the cyclically tested specimens in the corrosive environment at $650{ }^{\circ} \mathrm{C}$. Fig. 10 shows the development of the BCC layers at the surface after 2 cycles in Fig. 10 a) and c), and 5 cycles in Fig. 10 b) and d). After 2 cycles, a layer thickness of approximately $3 \mu \mathrm{m}$ was present and increased to approximately 2-5 $\mu \mathrm{m}$ and 2-10 $\mu \mathrm{m}$ after 5 and 10 cycles respectively (as seen in Fig. 10 and Fig. 11). The layers consisted of several $\mathrm{BCC}$ grains and the $\mathrm{BCC}$ grains were smaller than the $\mathrm{FCC}$ grains in the bulk material, as shown in Fig. 9, 10 and 11. In the overview image of the area, shown in Fig. 12, the BCC region could be observed by ECCI as well as light optical microscopy. The BCC structure in Fig. 12 was confirmed using EBSD, showed in Fig. 12 d), where BCC correspond to the blue color. The BCC was also observed internally at the grain boundaries where carbides formed, see Fig. 12 b) and e) for such an area. In Fig. 13 a) the typical element concentration of $\mathrm{O}, \mathrm{Cr}, \mathrm{Fe}, \mathrm{Ni}, \mathrm{Mn}$ and $\mathrm{Si}$ over a $\mathrm{BCC}$ region (Fig. $13 \mathrm{~b})$ ) after 10 cycles is given using a EDS line scan. The BCC region showed Cr and Mn depletion. This can also be observed in Fig. 5 c) and e); below the Cr-rich oxide, a $\mathrm{Cr}$ and $\mathrm{Mn}$ depleted area can be observed. This was also confirmed by EDS and WDS point scans of the BCC region after 10 cycles, using WDS for Mn and EDS for all other elements. The average chemical composition from 12 point scans in wt.\% was found to be:

Si $0.41 \pm 0.04, \mathrm{Mn} 0.6 \pm 0.14$, Cr $11.56 \pm 1.08$, Ni $12.73 \pm 0.81$ and $\mathrm{Fe}$ $74.24 \pm 0.82$, where the given scatter equals one standard deviation. In Fig. 5 c) and e), the increase of the BCC thickness with the number of cycles can also be seen. 


\section{Discussion}

\subsection{Formed oxides}

From Fig. 4 and Table 1, mainly four different types of oxides were observed. Together with the GI-XRD results in Fig. 3 and EDS/WDS line scans in Fig. 5, the main oxides are most likely: 1) the outer oxide is $\mathrm{Fe}_{2} \mathrm{O}_{3}$ or an Fe-rich $\left.(\mathrm{Fe}, \mathrm{Cr})_{2} \mathrm{O}_{3}, 2\right)$ at the metal surface there is a Cr-rich $(\mathrm{Cr}, \mathrm{Fe})_{2} \mathrm{O}_{3}$,

3 ) the inward growing oxides are presumably a Ni-rich (Cr, $\mathrm{Fe}, \mathrm{Ni}_{3} \mathrm{O}_{4}$ and 4) a Ni-poor $(\mathrm{Cr}, \mathrm{Fe}, \mathrm{Ni})_{3} \mathrm{O}_{4}$ spinel oxides. The ECCI-image in Fig. 14 indicates the locations of the four main oxides. The observed oxides are essentially the same as Halvardsson et al. [12] observed in an AISI 304 subjected to isotherm heating at $600{ }^{\circ} \mathrm{C}$ in a water vapour medium. The work by Croll and Wallwork[26] supports the presence of a Ni-rich and a Ni-poor $(\mathrm{Cr}, \mathrm{Fe}, \mathrm{Ni})_{3} \mathrm{O}_{4}$, since they shows that $\mathrm{Ni}$ is fully soluble in a $\mathrm{Fe}-\mathrm{Ni}-\mathrm{Cr}$ spinel with Cr-content below 14 at.\% and arbitrarily $\mathrm{Fe} / \mathrm{Ni}$ ratio. Other possible oxides that are present include the spinels $\mathrm{Mn}_{1.5} \mathrm{Cr}_{1.5} \mathrm{O}_{4}, \mathrm{NiCr}_{2} \mathrm{O}_{4}$ and $\mathrm{FeCr}_{2} \mathrm{O}_{4}$. The presence of $\mathrm{Mn}_{1.5} \mathrm{Cr}_{1.5} \mathrm{O}_{4}$ is supported by the EDS/WDS results shown in Fig. 5 a). The other two spinel oxides have not been observed but their XRD peaks are close to those of $(\mathrm{Cr}, \mathrm{Fe}, \mathrm{Ni})_{3} \mathrm{O}_{4}$ and are therefore hard to discern; their presence have been reported by others [14].

In Fig. 3, as the angle of incidence increases from $2^{\circ}$ to $10^{\circ}$, different oxides and phases appear in the spectrum. Since the oxides are thick after 20 thermal cycles in humidified air, only the strongest peaks from the bulk material (FCC) and the $\alpha^{\prime}$ martensite (BCC) are observed at $10^{\circ}$ incidence angle. 


\subsection{Formation of $\alpha^{\prime}$ martensite}

As for previous studies, $\alpha^{\prime}$ martensite was observed internally at grain boundaries, and presumably formed through previously described mechanisms of carbide formation at grain boundaries [21, 22, 24]. The more extensive $\alpha^{\prime}$ martensite formation observed at the specimen surface is considered to be caused by $\mathrm{Cr}$ depletion through a combination of carbide formation and oxidation [21, 23, 24]. Fig. 13 and Fig. 5 c) and e) show a similar depletion of $\mathrm{Cr}$ and Mn where the $\alpha^{\prime}$ martensite layer was found, as reported by others $[23,24]$. The reason for the presence of the FCC area between the oxide and the $\mathrm{BCC}$ region in Fig.13 is believed to be the higher level of Ni that suppress $\alpha$ ' martensite formation [27]. It should be noted that the relatively even $\mathrm{Cr}$ level in the Cr depleted area, where the $\alpha^{\prime}$ martensite layer formed, suggests a high $\mathrm{Cr}$ diffusivity in this region; otherwise, a $\mathrm{Cr}$ gradient through the $\alpha^{\prime}$ martensite layer would have been observed. Since the $\alpha^{\prime}$ martensite layer consists of several grains and these grains are considerably smaller than the grains of the FCC matrix, the number of grain boundaries is much higher in the $\alpha^{\prime}$ martensite layer compared to the FCC matrix. Since the diffusivity of Cr is much faster in grain boundaries compared to bulk diffusion $[28,20]$ this will cause a relatively even $\mathrm{Cr}$ level instead of a gradient in the $\mathrm{Cr}$ depleted area.

The $\alpha^{\prime}$ martensite layer is growing thicker with increasing number of cycles, see Fig. 10 - 11. This is attributed to the Cr depletion at the interface between the bulk material and the $\alpha^{\prime}$ martensite layer during the hot part

of the cycle. This $\mathrm{Cr}$ depletion will generate a small area with a chemical composition that enables transformation to $\alpha^{\prime}$ martensite during the cooling. 
To serve as basis for the discussion, a number of Thermo-Calc [29] and Dictra [28] simulations were performed to find plausible mechanisms for $\alpha^{\prime}$ martensite formation and growth at the specimens surface. The initial stages of the tests were modelled in a few different ways. A number of simplifications were necessary; the following points describes the model assumtions:

1. Prior to oxidation, the material was exposed to a heat treatment. During this heat treatment, $\mathrm{Cr}$ depletion was assumed to occur at the outermost part of the FCC grain due to carbide formation. The influence of oxidation was neglected during the first cycle.

2. Since $\mathrm{C}$ diffusivity, $D_{C}^{F C C}$, is much higher than $\mathrm{Cr}$ diffusivity, $D_{C r}^{F C C}$, in FCC-Fe, the $\mathrm{C}$ content at the surface during the heat treatment was assumed to remain close to the nominal value of 0.015 wt.\% due to outward diffusion from the FCC grain. A Thermo-Calc simulation suggested that the $\mathrm{Cr}$ content in the FCC phase at the outermost part of the grain should then drop to $\sim 5.2$ wt.\%. Inserting this in Fick's second law, see Eq. 2, gave the Cr profile after the heat treatment as shown in Fig. 15. This Cr profile was used as input for the oxidation modelling.

$$
\frac{C_{s}-C_{x}}{C_{s}-C_{0}}=\operatorname{erf}\left(\frac{x}{2 \sqrt{D t}}\right)
$$

3. During oxidation, carbide formation was neglected since: 1) the $\alpha$ ' martensite layers observed at the specimen surface were larger than those observed internally at grain boundaries, indicating that oxidation dominated at the surface, and 2) oxidation in lab air gave considerable 
lower $\mathrm{Cr}$ depletion, again indicating that $\mathrm{Cr}$ removal due to oxidation dominated in moist air.

4. The Cr profile were used with Eq. 3, from reference [27] where $w_{i} \%$ is the content of element $i$, to establish the size of the $\alpha^{\prime}$ martensite layer that formed during cooling. The minimum temperature of the cycle, $100{ }^{\circ} \mathrm{C}$, was used as a criterion for $\alpha^{\prime}$ martensite transformation. The influence of Mn, Si and N was neglected.

$$
M_{s}=1302-42 w_{\mathrm{Cr}} \%-61 w_{\mathrm{Ni}} \%-33 w_{\mathrm{Mn}} \%-28 w_{\mathrm{Si}} \%-1667\left(w_{\mathrm{C}} \%+w_{\mathrm{N}} \%\right)
$$

An oxidation-diffusion simulation was performed using the commercial software Dictra coupled with an oxidation routine written in-house. The model has previously been described by Yuan et al. [30]. The simulation was first performed on a FCC grain with an outer BCC region. The result after the first oxidation cycle is presented in Fig. 16 a). While the faster $\mathrm{Cr}$ diffusivity in BCC-Fe did give a $\mathrm{Cr}$ depleted area, just as observed experimentally, the $\mathrm{BCC}$ region also caused inwards diffusion of $\mathrm{Ni}$ giving rise to a Ni peak in the FCC region just beneath the BCC region. This Ni peak would prevent the $\mathrm{BCC}$ region to grow as $\mathrm{Ni}$ enrichment would lower the $M_{s}$ temperature. Furthermore, the Ni content in the BCC region dropped to levels significantly lower than those observed experimentally. It can hence be concluded that the $\mathrm{BCC}$ region transforms back to $\mathrm{FCC}$ at $650{ }^{\circ} \mathrm{C}$; this is also supported by the phase diagram presented in Fig. 17 for Fe-12.5 wt.\% $\mathrm{Ni}-x \mathrm{Cr}$ which shows that the material enters the $\gamma$-loop at reheating to 650 ${ }^{\circ} \mathrm{C}$. 
Since the relatively even $\mathrm{Cr}$ level in the depleted area, observed experimentally in the $\alpha^{\prime}$ martensite, must have been formed due to fast $\mathrm{Cr}$ diffusivity, two other possible mechanisms were tested: 1) the BCC structure is maintained for some time during heating, but eventually transform to FCC, and 2) the BCC transfer immediately to FCC upon heating, but the smaller grains in the $\alpha^{\prime}$ martensite area give increased $\mathrm{Cr}$ diffusivity due to grain boundary diffusion. Dictra simulations were performed in accordance with these assumptions. For the first case, the BCC phase was modelled to remain for 1 hour, but then transformed to FCC; for the second case, Dictra's builtin grain boundary diffusion model was used with a grain boundary width of $5 \cdot 10^{-10} \mathrm{~m}[31]$ and a grain size of $10^{-7} \mathrm{~m}$.

As seen in Fig. 16 b) and c), letting the BCC transform back to FCC at high temperature removed the Ni peak observed in Fig. 16 a) and gave a better agreement with experimental observations. Adding grain boundaries to the outer layer increased the Cr diffusivity; as seen in Fig. 16 c). The finer grain structure in the outer layer would thus aid chromia formation at the surface and with time become depleted in Cr. Based on the Thermo-Calc and Dictra simulations, it is considered likely that the formed $\alpha^{\prime}$ martensite layer transforms back to $\mathrm{FCC}$ at $650^{\circ} \mathrm{C}$, and that the $\mathrm{Cr}$ depleted area observed in the $\alpha^{\prime}$ martensite layer is formed at $650{ }^{\circ} \mathrm{C}$ due to increased $\mathrm{Cr}$ diffusivity in the $\alpha^{\prime}$ martensite layer caused by grain boundary diffusion.

Fig. 18 shows the $\mathrm{C}$ profile after 100 hours of oxidation-diffsuion; it can be seen that $\mathrm{C}$ diffuses from the $\mathrm{BCC}$ region inwards into the grain. It should therefore also be possible for further carbide precipitation to occur in the $\mathrm{BCC} / \mathrm{FCC}$ interface as $\mathrm{C}$ is pushed towards that region from the $\mathrm{BCC}$ 
region. Due to the faster Cr diffusivity in the transformed region, the FCC region, even though far from the surface where oxidation occurs, will continue to be depleted of $\mathrm{Cr}$.

\subsection{The influence of $\alpha^{\prime}$ martensite on corrosion}

The formation of $\alpha^{\prime}$ martensite at the surface influence the corrosion process, similarly to grain refinement approaches $[11,14,17]$. The $\alpha$ ' martensite

formation causes an increase in the number of grain boundaries at the surface (see Fig. 9 - 11) and subsequently locally improves the supply of $\mathrm{Cr}$ to the protective oxide scale at the surface through grain boundary diffusion. In the microstructure, this is supported by Fig. 19 a) where a Cr-rich protective scale is formed above the $\alpha^{\prime}$ martensite layer (BCC). This should be compared to Fig. 19 b) where the bulk material is consumed by inwards growing oxides. For this reason, areas that lack the $\alpha^{\prime}$ martensite are more consumed by inward corrosion than the areas with $\alpha^{\prime}$ martensite; this can be seen in Fig. 7. Fig. 14 also supports a positive effect of the $\alpha^{\prime}$ martensite formed at austenite grain boundaries at the surface, showing a thinner $\mathrm{Fe}_{2} \mathrm{O}_{3}$ scale above the $\alpha$ ' martensite region (indicated by arrows) and a Crrich $(\mathrm{Cr}, \mathrm{Fe})_{2} \mathrm{O}_{3}$ formed at the metal surface. However, the formation of $\alpha$ ' martensite in this alloy is unintended and not controlled, thus being far from as effective as dedicated grain refinement techniques. The positive effect of the formation of $\alpha^{\prime}$ martensite on the corrosion resistance is limited to local areas. 


\section{Conclusion}

In the present study, an AISI 304-type stainless steel was exposed to thermal cycling in humidified air in the temperature interval $100-650{ }^{\circ} \mathrm{C}$. The following conclusions could be made:

1. Four main oxide types are formed, they are most likely 1) the outer oxide is $\mathrm{Fe}_{2} \mathrm{O}_{3}$ or an Fe-rich $\left.(\mathrm{Fe}, \mathrm{Cr})_{2} \mathrm{O}_{3}, 2\right)$ at the metal surface there is a $\mathrm{Cr}$-rich $\left.(\mathrm{Cr}, \mathrm{Fe})_{2} \mathrm{O}_{3}, 3\right)$ the inward growing oxides are presumably a $\mathrm{Ni}$-rich $(\mathrm{Cr}, \mathrm{Fe}, \mathrm{Ni})_{3} \mathrm{O}_{4}$ and 4) a $\mathrm{Ni}$-poor $(\mathrm{Cr}, \mathrm{Fe}, \mathrm{Ni})_{3} \mathrm{O}_{4}$ spinel oxide.

2. $\alpha^{\prime}$ martensite forms during cooling from $650{ }^{\circ} \mathrm{C}$ to $100{ }^{\circ} \mathrm{C}$. This is due to $\mathrm{Cr}$ depletion caused by oxidation at the surface which locally rises the $M_{s}$ temperature.

3. The $\alpha$ ' martensite grows thicker with increasing numbers of cycles during the thermal cycling.

4. The $\alpha^{\prime}$ martensite transforms back to FCC at $650{ }^{\circ} \mathrm{C}$ during the thermal cycling.

5. The formation of $\alpha^{\prime}$ martensite will give several smaller grains at the surface, compared to the grains in the FCC matrix. Even though the $\alpha^{\prime}$ martensite transforms back to $\mathrm{FCC}$ at $650{ }^{\circ} \mathrm{C}$, the increased number of grain boundaries will improve the Cr diffusion within this region.

6. A Cr-rich protective scale is formed above the $\alpha^{\prime}$ martensite layer, due to the reason described in conclusion 5, compared to regions where no $\alpha^{\prime}$ martensite layer has formed. For this reason, areas that lack the $\alpha$ ' martensite are more consumed by inward corrosion and the outer oxide scale is thicker than at the areas with $\alpha^{\prime}$ martensite. Thus, the 
formation of $\alpha^{\prime}$ martensite is locally decreasing the in- and outward scale growth.

\section{Acknowledgements}

Present study was financially supported by AB Sandvik Materials Technology in Sweden and the Swedish National Energy Administration through the Research Consortium of Materials Technology for Thermal Energy Processes, Grant No. KME-701. Agora Materiae and AFM Strategic Faculty Grant SFO-MAT-LiU\#2009-00971 at Linköping University are also acknowledged. Dr Biplab Paul is acknowledged for the XRD measurements. 


\section{References}

[1] A. Phongphiphat, C. Ryu, Y. B. Yang, K. N. Finney, A. Leyland, V. N. Sharifi, J. Swithenbank, Corrosion Science 52 (2010) 3861-3872.

[2] J. Pettersson, H. Asteman, J.-E. Svensson, L.-G. Johansson, Oxidation of Metals 64 (2005) 23-41.

[3] I. G. Wright, R. B. Dooley, International Materials Reviews 55 (2010) 129-167.

[4] H. Asteman, J.-E. Svensson, L.-G. Johansson, M. Norell, Oxidation of Metals 52 (1999) 95-111.

[5] H. Asteman, J.-E. Svensson, M. Norell, L.-G. Johansson, Oxidation of Metals 54 (2000) 11-26.

[6] S. Henry, A. Galerie, L. Antoni, Materials Science Forum 369-372 (2001) 353-360.

[7] H. Asteman, J.-E. Svensson, L.-G. Johansson, Corrosion Science 44 (2002) 2635-2649.

[8] A. Yamauchi, K. Kurokawa, H. Takahashi, Oxidation of Metals 59 (2003) 517-527.

[9] H. Asteman, J.-E. Svensson, L.-G. Johansson, Journal of The Electrochemical Society 151 (2004) B141-B150.

[10] H. Asteman, K. Segerdahl, J.-E. Svensson, L.-G. Johansson, M. Halvarsson, J. Tang, Materials Science Forum 461-464 (2004) 775-782. 
[11] X. Peng, J. Yan, Y. Zhou, F. Wang, Acta Materialia 53 (2005) 50795088 .

[12] M. Halvarsson, J. Tang, H. Asteman, J.-E. Svensson, L.-G. Johansson, Corrosion Science 48 (2006) 2014-2035.

[13] N. K. Othman, J. Zhang, D. J. Young, Corrosion Science 52 (2010) $2827-2836$.

[14] J. Zhang, X. Peng, D. J. Young, F. Wang, Surface \& Coating Technology 217 (2013) 162-171.

[15] H. Asteman, K. Segerdahl, J.-E. Svensson, L.-G. Johansson, Materials Science Forum 369-372 (2001) 277-286.

[16] R. Peraldi, B. A. Pint, Oxidation of Metals 61 (2004) 463-483.

[17] R. S. Raman, R. K. Gupta, Corrosion Science 51 (2009) 316-321.

[18] J. Horváth, R. Birringer, H. Gleiter, Solid State Communications 62 (1987) 319-322.

[19] Y. Kolobov, G. Grabovetskaya, M. Ivanov, A. Zhilyaev, R. Valiev, Scripta materialia 44 (2001) 873-878.

[20] Z. Wang, N. Tao, W. Tong, J. Lu, K. Lu, Acta Materialia 51 (2003) 4319-4329.

[21] E. P. Butler, M. G. Burke, Acta Materialia 34 (1986) 557-570.

[22] C. K. Mukhopadhyay, K. V. Kasiviswanathan, T. Jayakumar, B. Raj, Scripta Materialia 30 (1994) 303-307. 
[23] D. F. Susan, G. A. Knorovsky, C. V. Robino, J. R. Michael, M. A. Rodriguez, M. J. Perricone, Science and Technology of Welding and Joining 17 (2012) 321-332.

[24] A. L. Fontaine, H.-W. Yen, P. Trimby, S. Moody, S. Miller, M. Chensee, S. Ringer, J. Cairney, Corrosion Science 85 (2014) 1 - 6.

[25] I. Gutierrez-Urrutia, S. Zaefferer, D. Raabe, Scripta Materialia 61 (2009) $737-740$.

[26] J. E. Croll, G. R. Wallwork, Oxidation of Metals 1 (1969) 55-71.

[27] J. A. H. Eichelman, F. C. Hul, Transactions of the American Society of Metals 45 (1953) 77-104.

[28] A. Brogenstam, A. Enström, L. Höglund, J. Ågren, Journal of Phase Equilibria 21 (2000) 269-280.

[29] B. Sundman, B. Jansson, J.-O. Andersson, Calphad 9 (1985) 153-190.

[30] K. Yuan, R. Eriksson, R. L. Peng, X.-H. Li, S. Johansson, Y.-D. Wang, Surface \& Coatings Technology 232 (2013) 204-215.

[31] D. Prokoshkina, V. Esin, G. Wilde, S. Divinski, Acta Materialia 61 (2013) 5188-5197.

[32] Thermo-Calc Software TCFE7 Steels/Fe-alloys database version 7, Accessed 11 Mars 2014. 


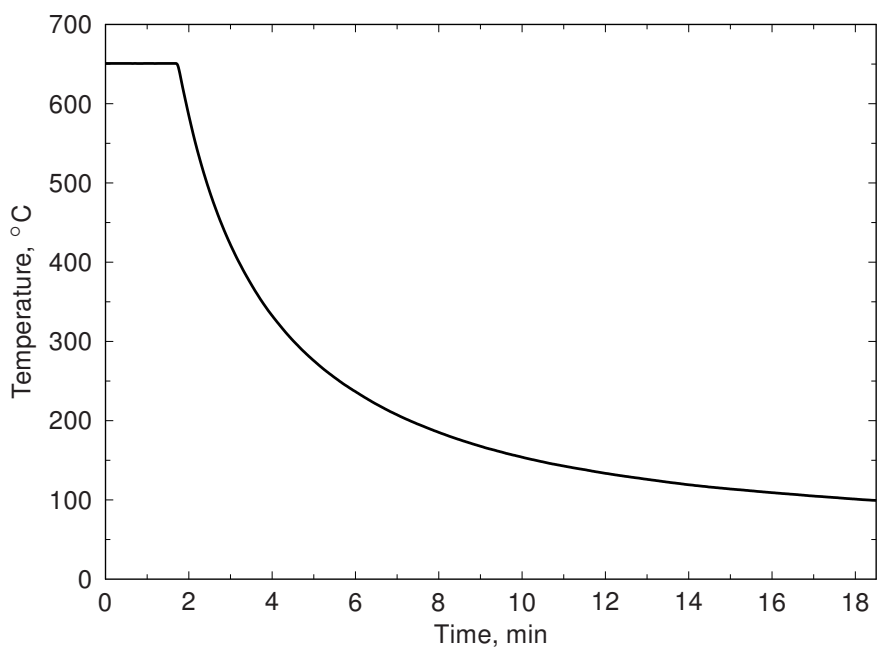

Figure 1: Temperature curve showing the cooling of the specimens. 


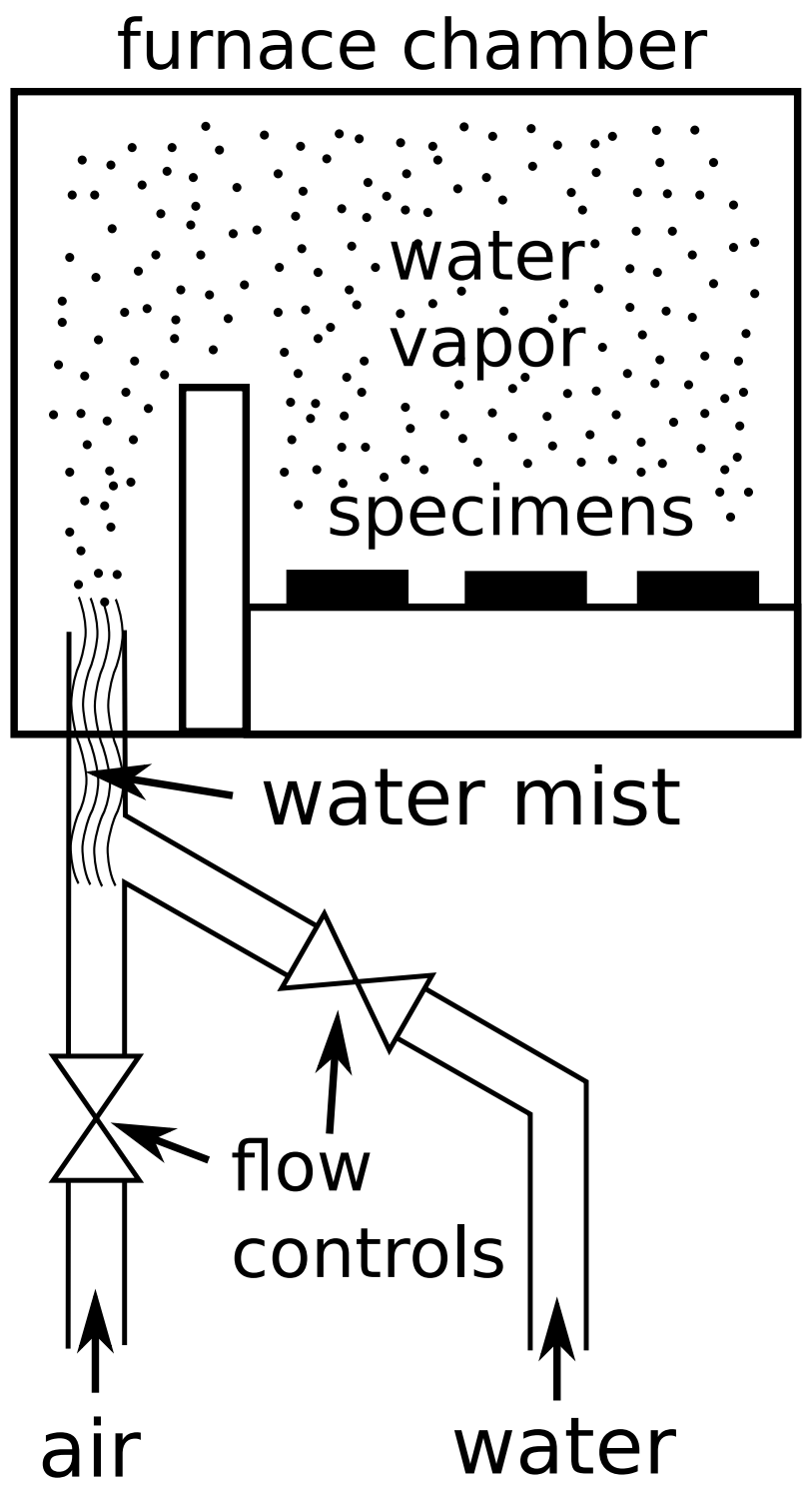

Figure 2: The corrosion rig setup. The furnace chamber can move up and down to achieve thermal cycling. 


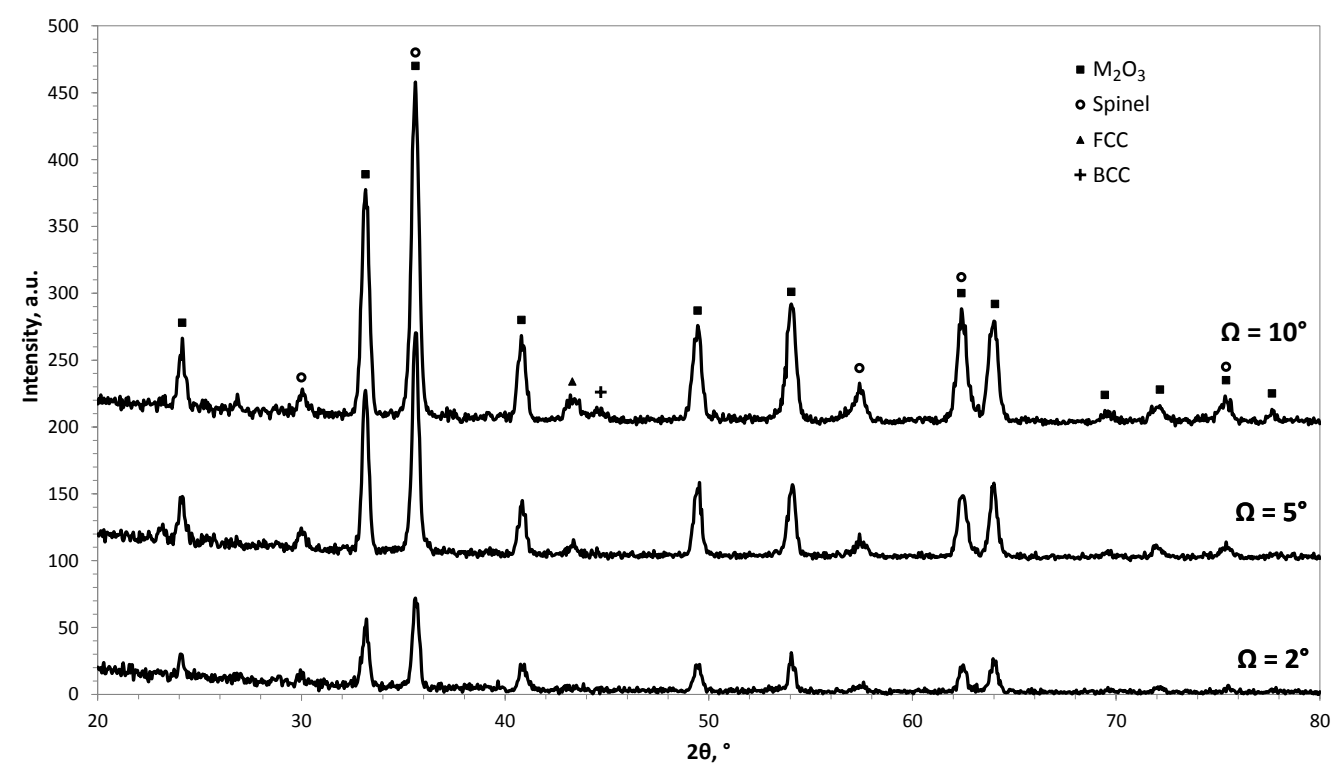

Figure 3: GI-XRD results using angles of incidence of $2^{\circ}, 5^{\circ}$ and $10^{\circ}$ after 20 thermal cycles between $100{ }^{\circ} \mathrm{C}$ and $650{ }^{\circ} \mathrm{C}$ in $\sim 15 \mathrm{~mol} \%$ water vapour. 

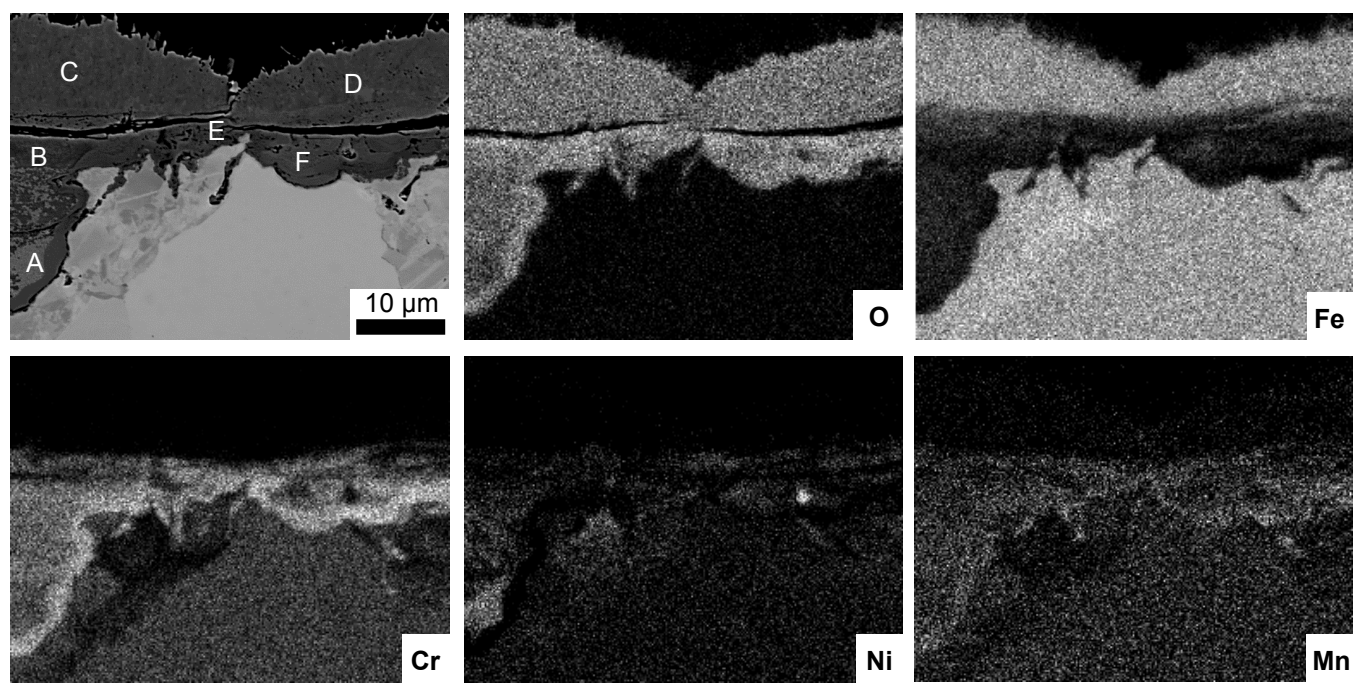

Figure 4: EDS maps showing the $\mathrm{O}, \mathrm{Fe}, \mathrm{Cr}, \mathrm{Ni}$ and $\mathrm{Mn}$ distributions after 10 thermal cycles between $100{ }^{\circ} \mathrm{C}$ and $650{ }^{\circ} \mathrm{C}$ in $\sim 15 \mathrm{~mol} \%$ water vapour. 
Table 1: Chemical composition of oxides in at.\% from EDS point analyses denoted A-F in Fig. 4. The results are from a specimen exposed to 10 thermal cycles between $100{ }^{\circ} \mathrm{C}$ and $650{ }^{\circ} \mathrm{C}$ in $\sim 15 \mathrm{~mol} \%$ water vapour.

$\begin{array}{lccccc}\text { Oxide } & \mathrm{O} & \mathrm{Cr} & \mathrm{Fe} & \mathrm{Ni} & \mathrm{Mn} \\ \mathrm{A} & 46.83 & 17.93 & 15.79 & 18.65 & 0.71 \\ \mathrm{~B} & 56.47 & 23.42 & 12.42 & 7.29 & 0.26 \\ \mathrm{C} & 58.52 & 0.95 & 40.24 & 0.12 & 0.16 \\ \mathrm{D} & 58.99 & 1.53 & 38.99 & 0.17 & 0.30 \\ \mathrm{E} & 57.76 & 24.83 & 12.49 & 4.11 & 0.73 \\ \mathrm{~F} & 57.27 & 19.92 & 13.72 & 8.65 & 0.36\end{array}$



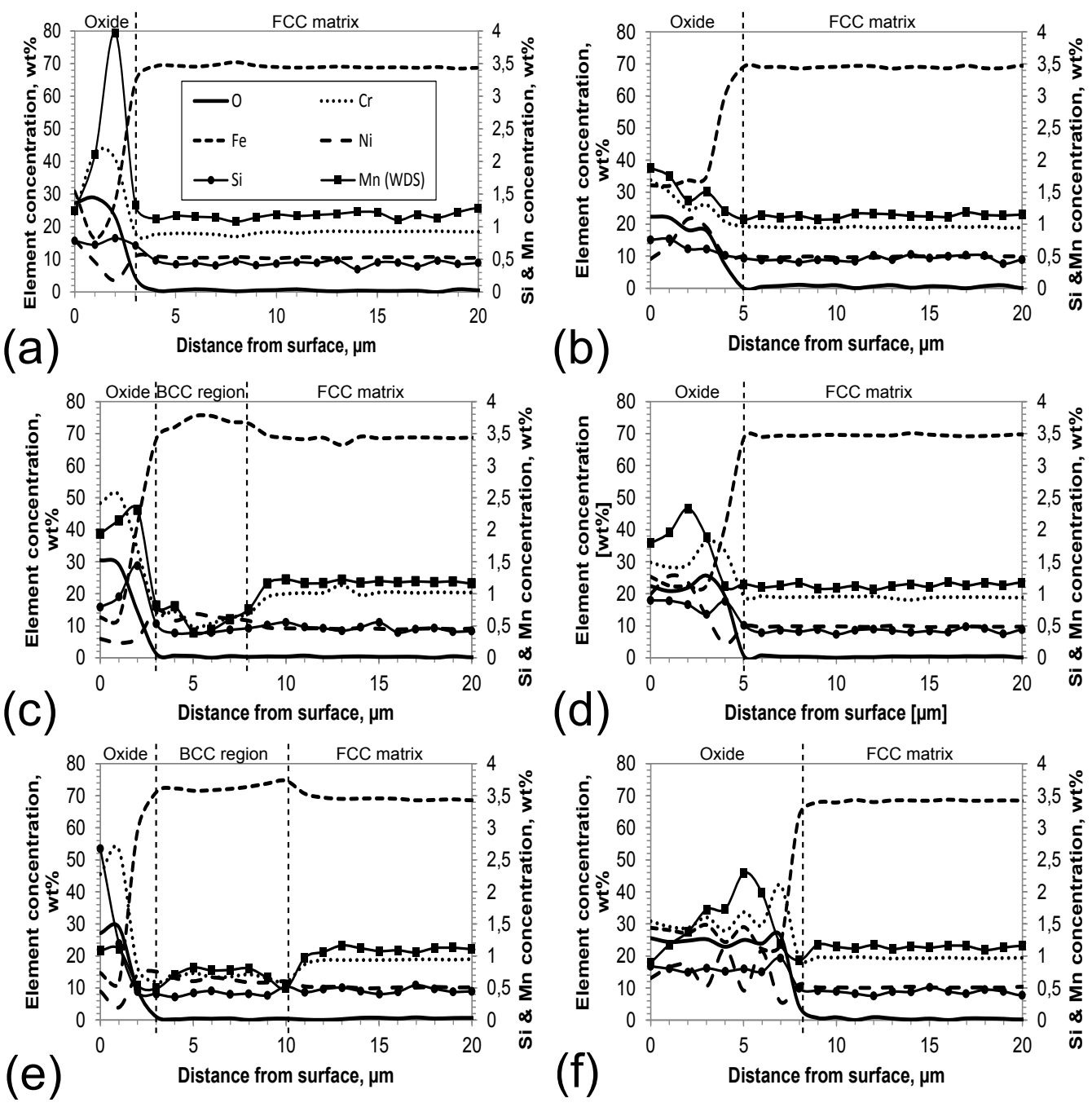

Figure 5: The development of oxides after thermal cycling between $100{ }^{\circ} \mathrm{C}$ and $650{ }^{\circ} \mathrm{C}$ in $\sim 15 \mathrm{~mol} \%$ water vapour for 2 cycles in a) and b), for 5 cycles in c) and d) and for 10 cycles in e) and f). a) represents an area with more Fe-rich oxide, c) and e) represent areas with more Cr-rich oxide and b), d) and f) represent areas with more Ni-rich and Fe-rich mixed oxide. Mn was detected using WDS and all other elements were detected using EDS. 

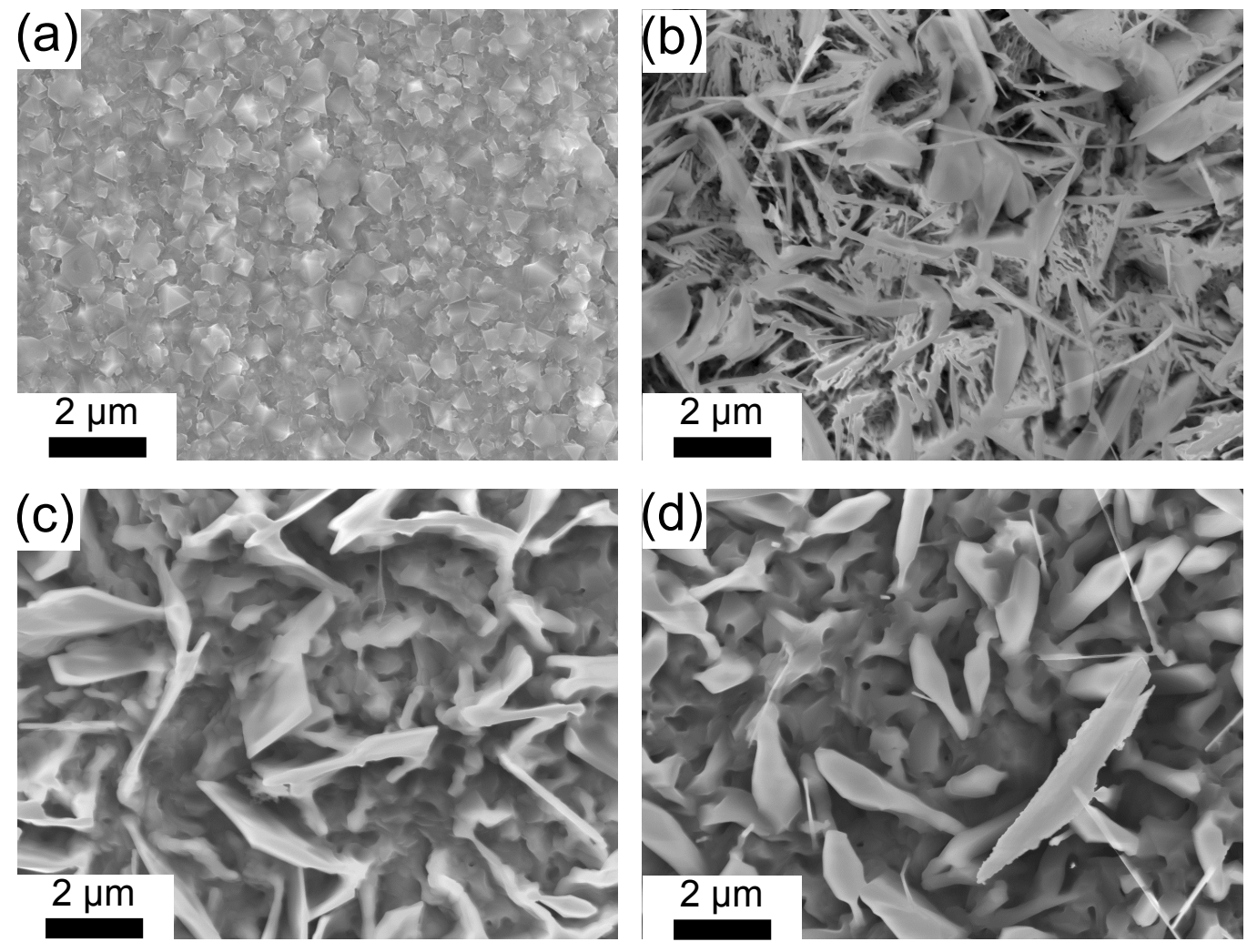

Figure 6: Top-views of the development of oxides, after 1000 hours static oxidation in air at $650{ }^{\circ} \mathrm{C}$, a), and after thermal cycling between $100{ }^{\circ} \mathrm{C}$ and $650{ }^{\circ} \mathrm{C}$ in $\sim 15 \mathrm{~mol} \%$ water vapour for: b) 2 cycles, c) 5 cycles and d) 10 cycles. 

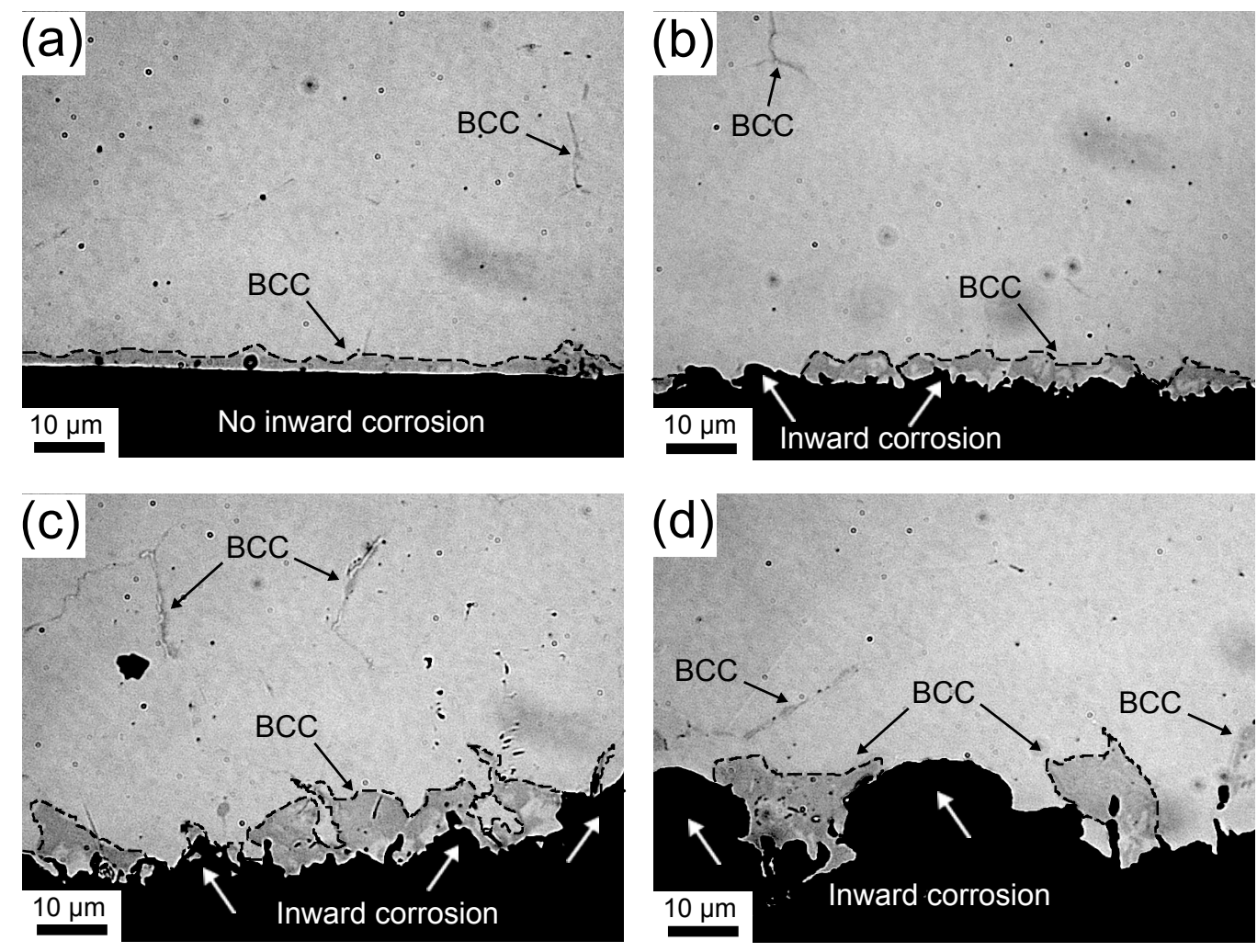

Figure 7: Cross-section LOM images of the development of $\alpha^{\prime}$ martensite (BCC) regions, after 1000 hours isothermal oxidation in air at $650{ }^{\circ} \mathrm{C}$, a), and after thermal cycling between $100{ }^{\circ} \mathrm{C}$ and $650{ }^{\circ} \mathrm{C}$ in $\sim 15$ mol\% water vapour for: b) 2 cycles, c) 5 cycles and d) 10 cycles. 

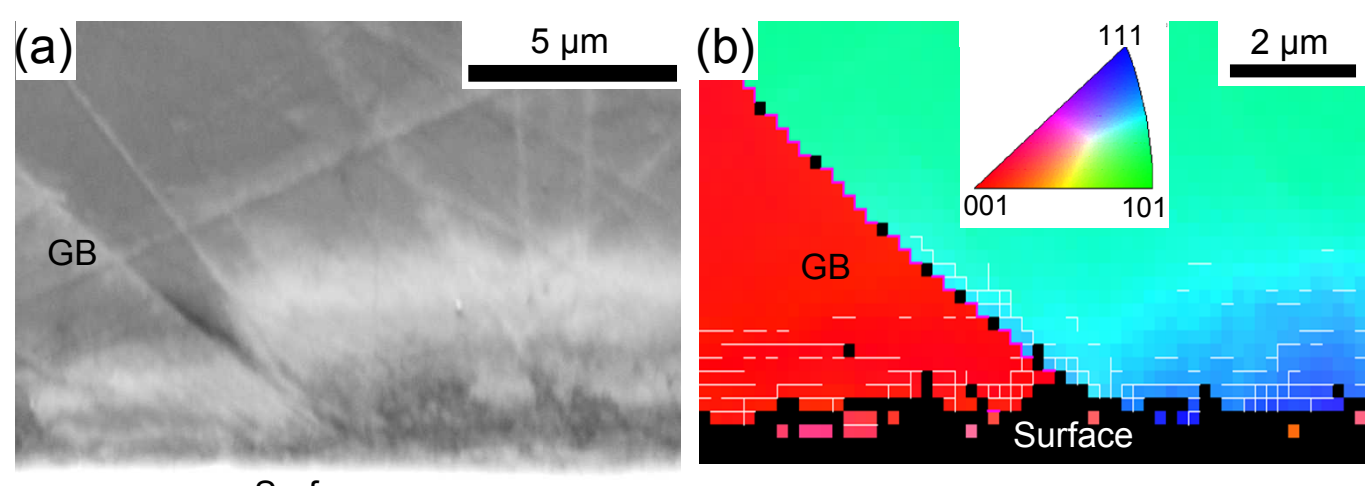

\section{Surface}

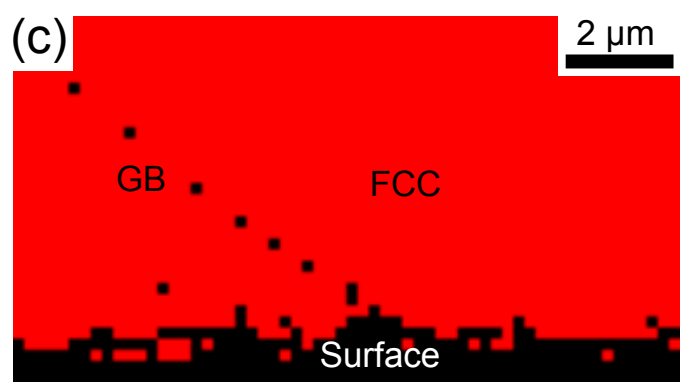

Figure 8: Microstructure after grinding: a) cross-section, b) crystallographic orientations from an inverse pole figure map, where the white lines correspond to low angle grain boundaries $\left(1^{\circ}-10^{\circ}\right)$. A high angle grain boundary $\left(>10^{\circ}\right)$ is also present and marked GB. c) shows a phase identification map where red corresponds to FCC. 


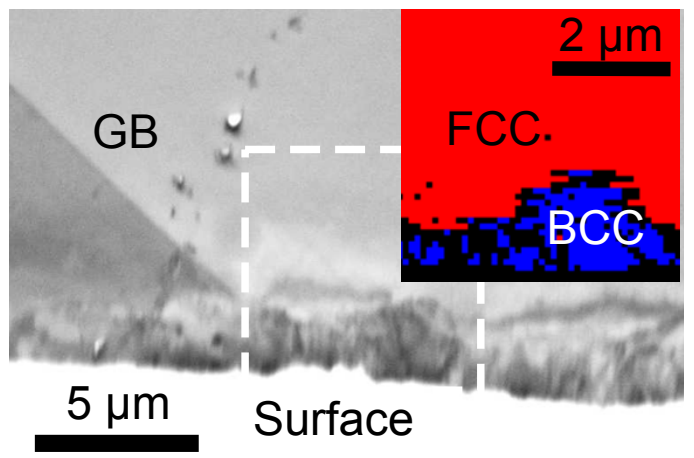

Figure 9: Microstructure shown on a cross-section after isothermal oxidation in air at 650 ${ }^{\circ} \mathrm{C}$ for 1000 hours, showing an $\alpha$ ' martensite (BCC) layer at the surface. In the phase identification map, red corresponds to FCC and blue corresponds to BCC. 

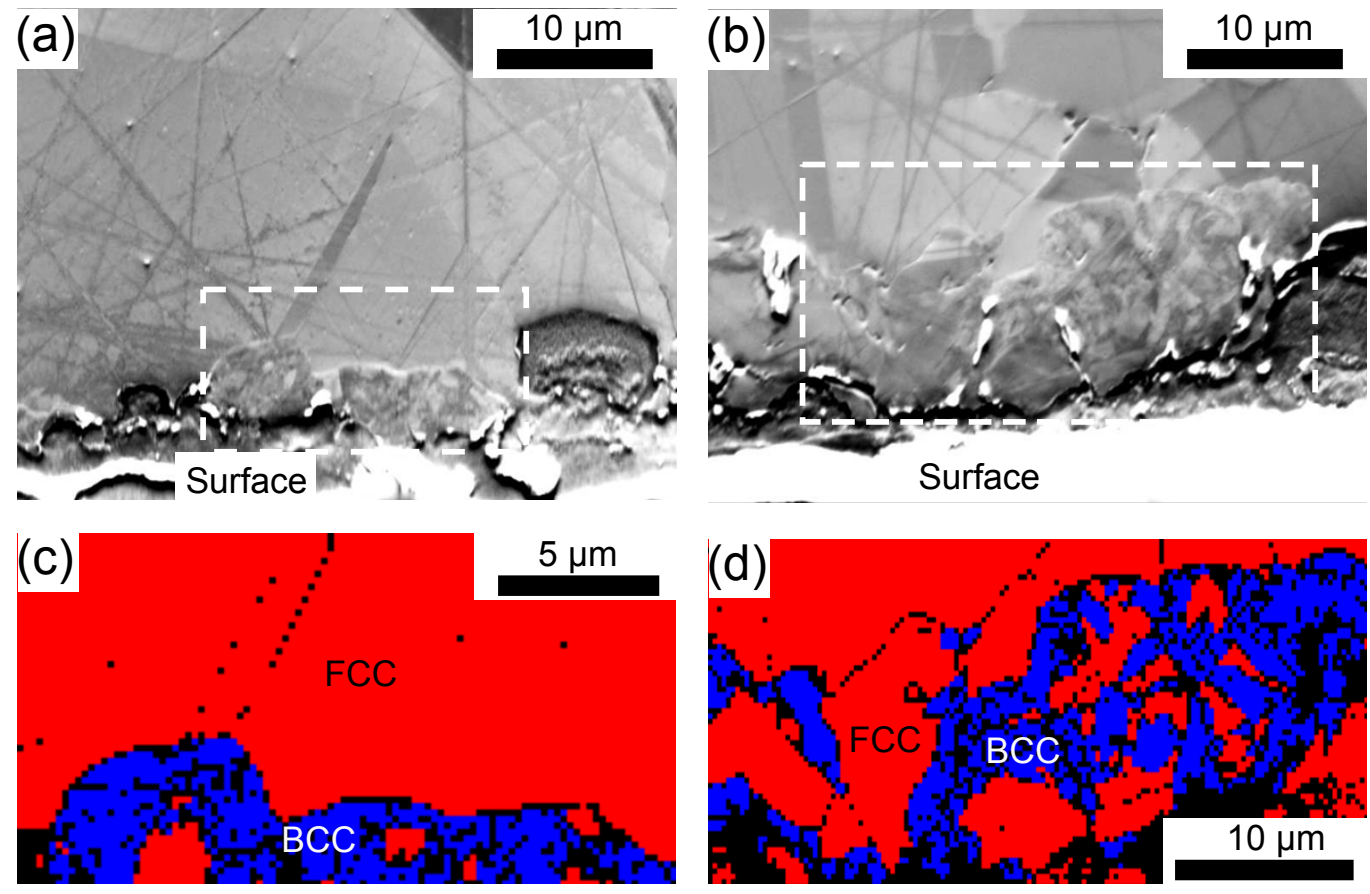

Figure 10: Microstructure after thermal cycling between $100{ }^{\circ} \mathrm{C}$ and $650{ }^{\circ} \mathrm{C}$ in $\sim 15 \mathrm{~mol} \%$ water vapour. Cross-sectioned specimens exposed to: a) 2 cycles and b) 5 cycles. The corresponding phase identification maps are shown in c) (2 cycles) and d) (5 cycles); red corresponds to FCC and blue corresponds to BCC. 

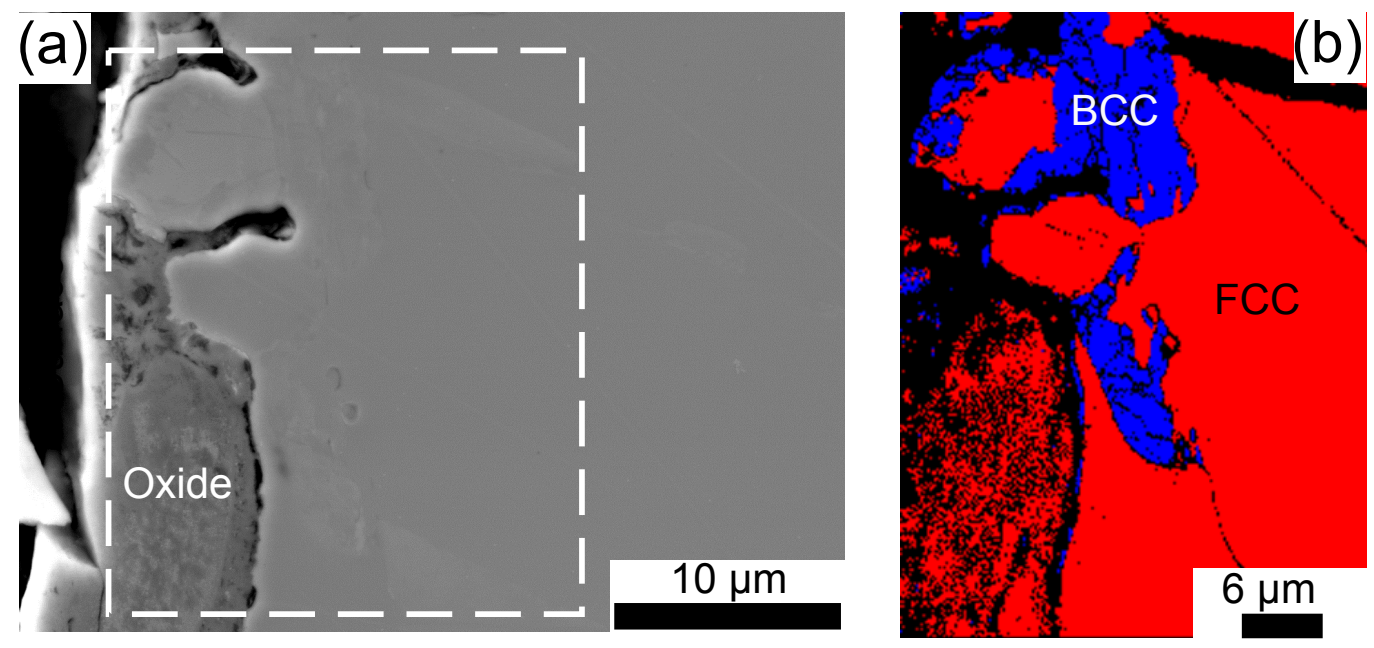

Figure 11: Microstructure after 10 thermal cycles between $100{ }^{\circ} \mathrm{C}$ and $650{ }^{\circ} \mathrm{C}$ in $\sim 15$ mol\% water vapour, showing: a) a cross-section and b) a phase identification map where red corresponds to FCC and blue corresponds to BCC. 

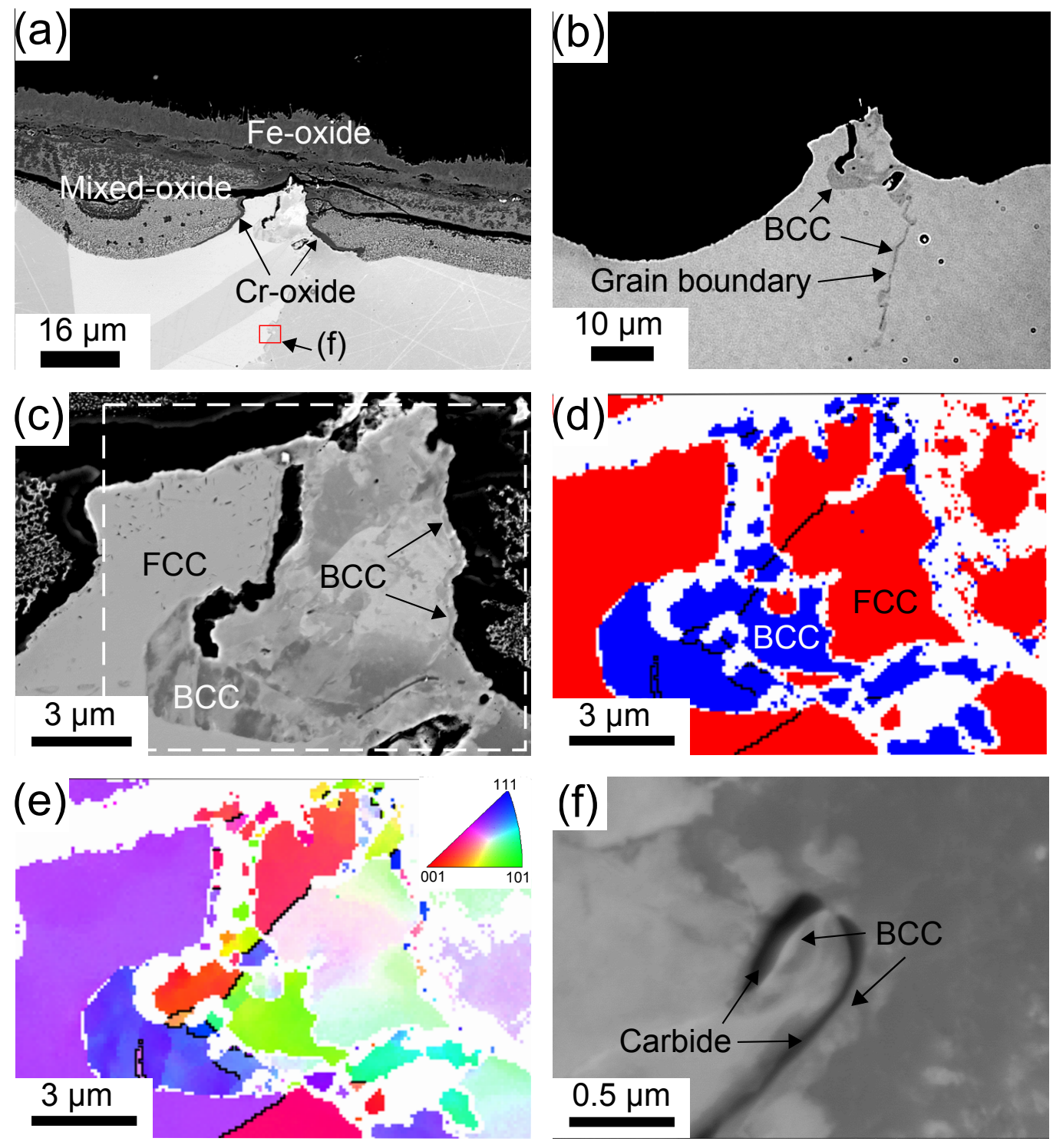

Figure 12: Microstructure after 10 thermal cycles between $100{ }^{\circ} \mathrm{C}$ and $650{ }^{\circ} \mathrm{C}$ in $\sim 15 \mathrm{~mol} \%$ water vapour showing: a) a cross-section with various oxides, b) a LOM image where $\alpha$ ' martensite (BCC) can be seen as darker fields, c) a magnification of the area with BCC, d) phase identification maps where red corresponds to FCC and blue corresponds to BCC e) crystallographic orientations from an IPF map and f) a magnification of internal BCC formed due to carbide formation at a grain boundary. 

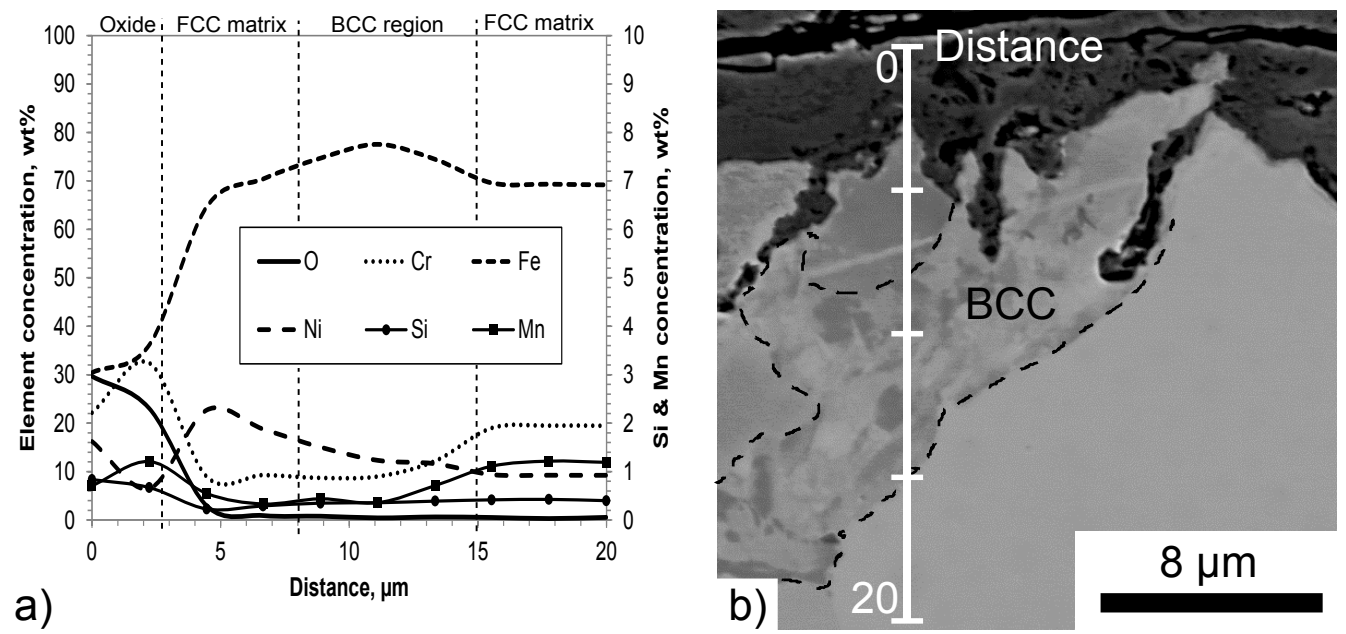

Figure 13: a) EDS line scan results after 10 thermal cycles between $100{ }^{\circ} \mathrm{C}$ and $650{ }^{\circ} \mathrm{C}$ in $\sim 15 \mathrm{~mol} \%$ water vapour. The $\alpha^{\prime}$ martensite (BCC) region shows a $\mathrm{Cr}$ and $\mathrm{Mn}$ depleted area. b) ECCI-image showing the analysed area in a), where the line scan and the BCC region are marked. 


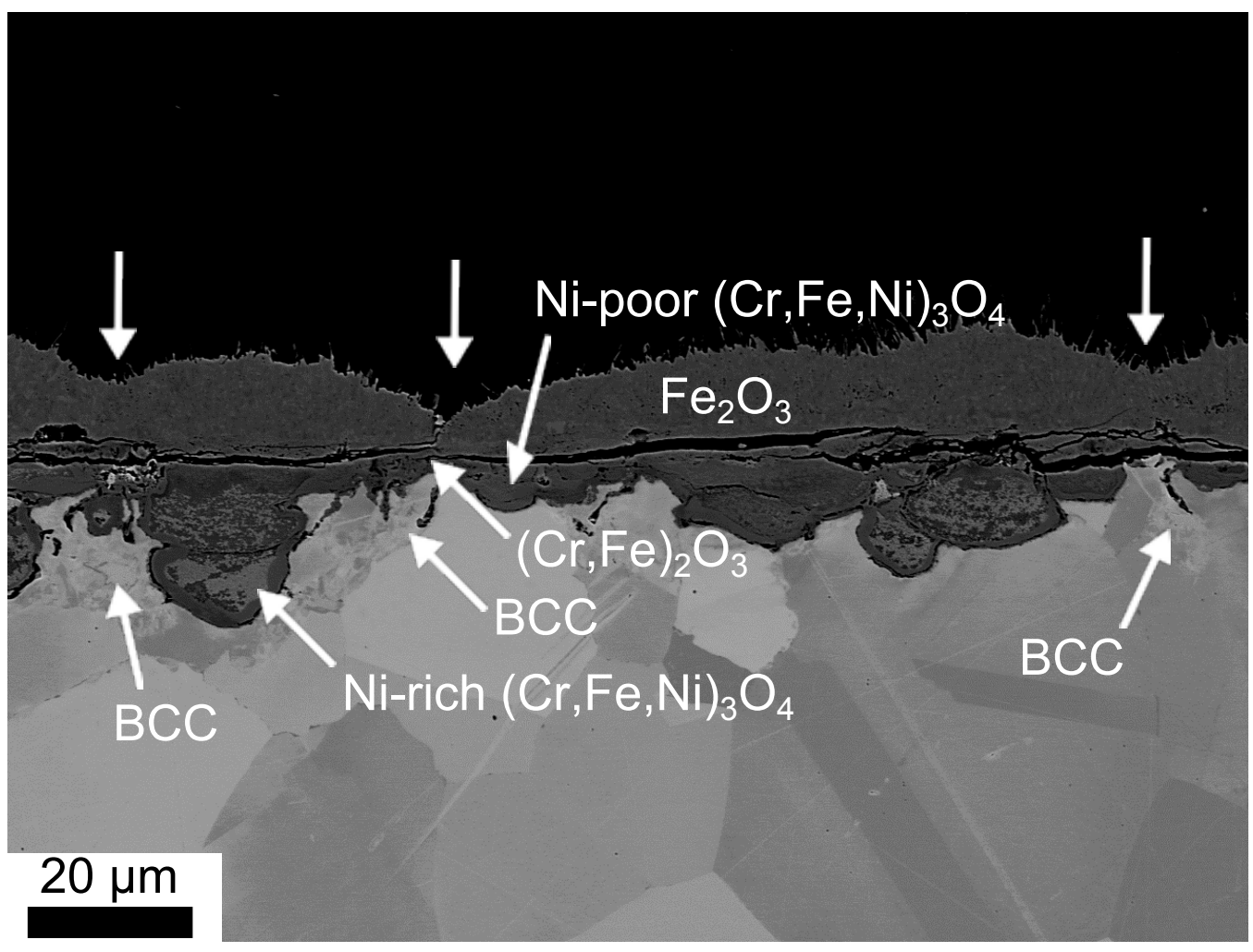

Figure 14: ECCI-image of the microstructure after 10 thermal cycles between $100{ }^{\circ} \mathrm{C}$ and $650{ }^{\circ} \mathrm{C}$ in $\sim 15 \mathrm{~mol} \%$ water vapour. The image shows the effect of grain boundary diffusion of $\mathrm{Cr}$, resulting in a thinner outer oxide layer (presumably $\mathrm{Fe}_{2} \mathrm{O}_{3}$ ) indicated by the three arrows at the $\alpha^{\prime}$ martensite $(\mathrm{BCC})$ regions. Above the $\alpha^{\prime}$ martensite there is a Cr-rich $(\mathrm{Cr}, \mathrm{Fe})_{2} \mathrm{O}_{3}$ scale on the metal surface, compared to the inward growing oxides (presumably a Ni-rich $(\mathrm{Cr}, \mathrm{Fe}, \mathrm{Ni})_{3} \mathrm{O}_{4}$ and a $\mathrm{Ni}$-poor $\left(\mathrm{Cr}, \mathrm{Fe}, \mathrm{Ni}_{3} \mathrm{O}_{4}\right.$ spinel oxides) next to it. 


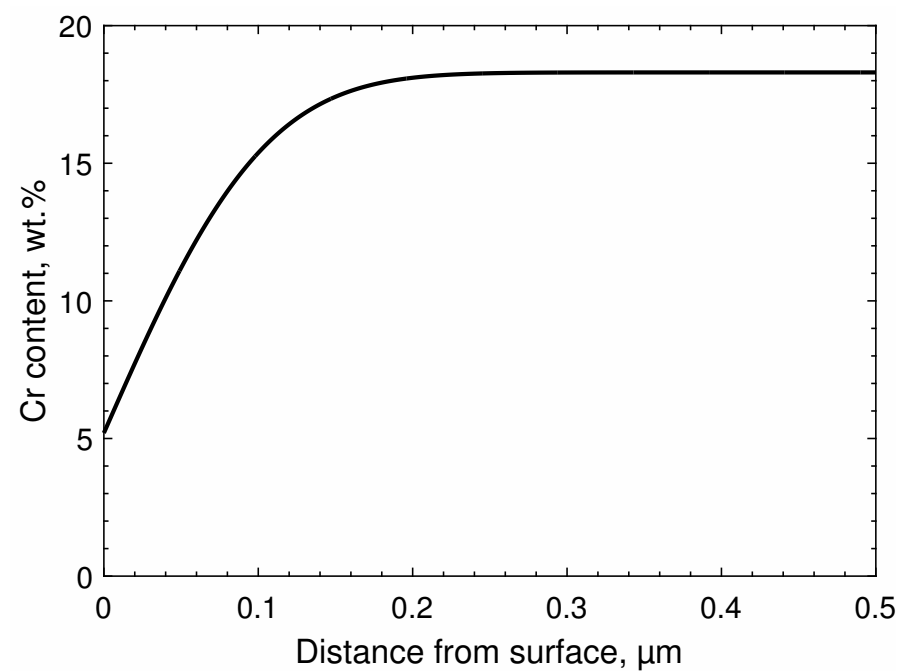

Figure 15: Cr content as function of distance from surface of a FCC grain used as input for Dictra simulation. The curve was established by assuming $\mathrm{Cr}$ consumption through carbide formation with a constant $\mathrm{C}$ content of 0.015 wt.\%. 

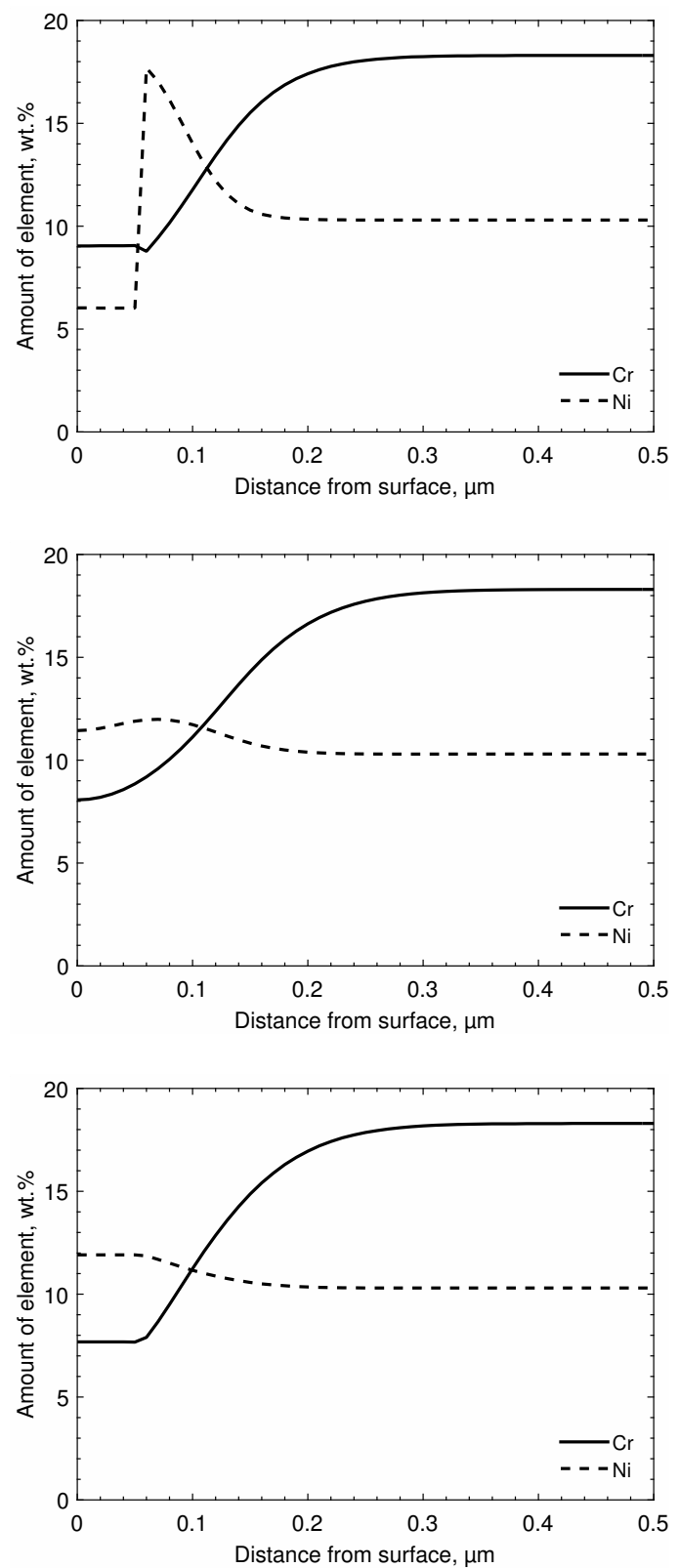

Figure 16: Modelled Cr profiles for several possible cases: a) BCC was retained as high temperature; b) $\mathrm{BCC}$ was retained $1 \mathrm{~h}$ at high temperature, then transformed to FCC; and c) BCC was transformed to FCC at high temperature but $\mathrm{Cr}$ diffusion was speed up by grain boundary diffusion. 


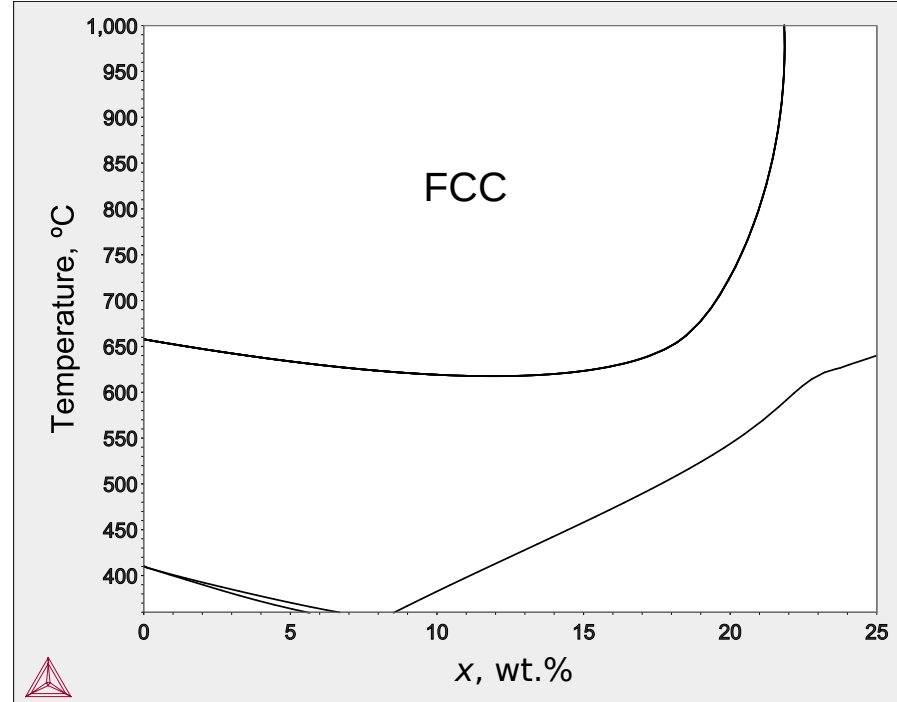

Figure 17: A Fe-12.5 wt.\% Ni- $x$ wt.\% Cr phase diagram expressed as a function of $x$. The $\mathrm{Cr}$ depleted region of the material entered the $\gamma$-loop at heating to $650{ }^{\circ} \mathrm{C}$. Data from Thermo-Calc Software TCFE7 Steels/Fe-alloys database version 7 [32]. 


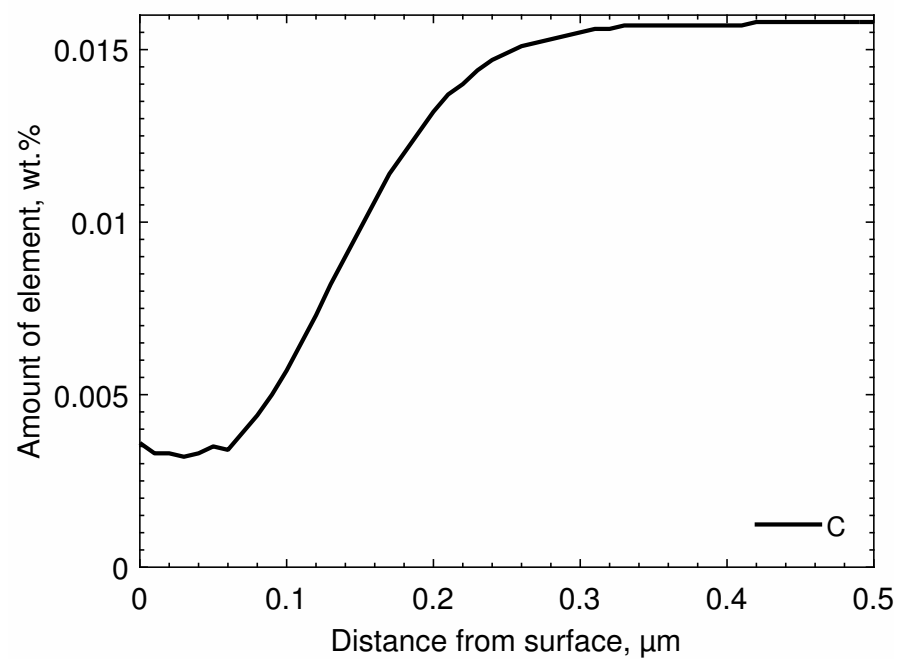

Figure 18: The corresponding C profile for the simulation in Fig. 16 c). 

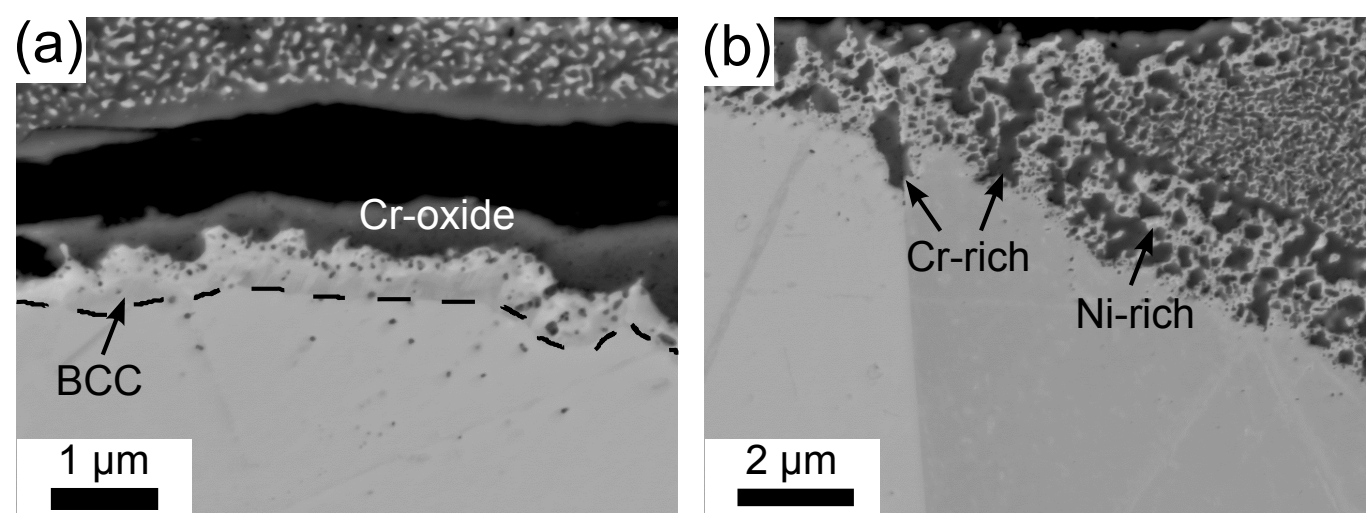

Figure 19: ECCI-image of the microstructure after 10 thermal cycles between $100{ }^{\circ} \mathrm{C}$ and $650{ }^{\circ} \mathrm{C}$ in $\sim 15 \mathrm{~mol} \%$ water vapour, showing: a) a Cr-oxide on top of a $\alpha$ ' martensite (BCC) layer and also small particles of Cr-oxide and in b) the consumption of the FCC matrix and formation of inward growing oxides. 